\title{
Comparing the Effectiveness of Schema Therapy (ST) and Emotional Schema Therapy (EST) on Clinical Syndromes of Individuals with Obsessive- Compulsive Symptoms (OCS)
}

\author{
Masood Ahovan ${ }^{1}$, Mahmood Jajarmi ${ }^{2 *}$, Abolfazl Bakhshipoor ${ }^{2}$
}

1. PhD student, Department of Counseling, Bojnourd Branch, Islamic Azad University, Bojnourd, Iran

2. Associate Professor, Department of Counseling, Bojnourd Branch, Islamic Azad University, Bojnourd, Iran

\begin{tabular}{|c|c|}
\hline Article Info & ABSTRACT \\
\hline & Introduction: Due to the prevalence of obsessiv \\
\hline Received: 2019/05/04; & delayed diagnosis and pharmacological treatment and the possibility of their recurrence \\
\hline Accepted: 2019/08/14; & after cognitive-behavioral therapies, it is necessary to plan some measures to prevent \\
\hline Published Online: 2020/01/17 & chronicity and recurrence of obsessive-compulsive disorder. The purpose of the present \\
\hline dol 10.30699/ajnn & $\begin{array}{l}\text { research was to compare the effectiveness of schema therapy and emotional schema } \\
\text { therapy on clinical syndromes of individuals with obsessive-compulsive symptoms. }\end{array}$ \\
\hline & $\begin{array}{l}\text { Methods: It was a semi-experimental research and included } 45 \text { individuals with } \\
\text { obsessive-compulsive symptoms who referred to Mehregan counseling center of }\end{array}$ \\
\hline $\begin{array}{l}\text { Use your device to scan } \\
\text { and read the article online }\end{array}$ & $\begin{array}{l}\text { Mashhad and were divided in schema therapy group ( } 15 \text { individuals), emotional schema } \\
\text { therapy group ( } 15 \text { individuals), and control group ( } 15 \text { individuals). Intervention groups }\end{array}$ \\
\hline 0 & received 20 individual schema therapy and 15 individual emotional schema therapy for \\
\hline 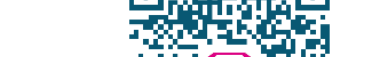 & 45 minutes per week, respectively. Data was obtained in four stages by obsessive- \\
\hline+4 & compulsive disorder scale of Maudsley, early maladaptive schema questionnaire of \\
\hline 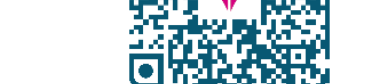 & $\begin{array}{l}\text { Young, and emotional schema scale of Leahy and also data analysis was carried out by } \\
\text { multi-variate variance analysis test. }\end{array}$ \\
\hline
\end{tabular}

Results: The results showed that there is significant difference in total score of obsessive-compulsive disorder between intervention and control groups $(\mathrm{P}<0.05)$. The results of paired comparison showed that there is no significant difference in total score of obsessive-compulsives between schema therapy group and emotional schema therapy group $(\mathrm{P}>0.05)$.

Conclusion: It seems that both methods of schema therapy and emotional schema therapy may be effective on improving symptoms of individuals with obsessivecompulsive disorder.

Keywords: Obsessive-compulsive Disorder, Schema therapy, Emotional schema therapy, Obsessive-compulsive symptoms

\section{How to Cite This Article:}

Ahovan M, Jajarmi M, Bakhshipoor A. Comparing the Effectiveness of Schema Therapy (ST) and Emotional Schema Therapy (EST) on Clinical Syndromes of Individuals with Obsessive-Compulsive Symptoms (OCS). Avicenna J Nurs Midwifery Care. 2020; 28 (3) :239-250 


\title{
مقايسه اثربخشى طرحواره درمانى (ST) و طرحواره درمانى هيجانى (EST) بر نشانعان بالينى افراد مبتلا به علائم وسواسى - جبرى (OCS)
}

\section{مسعود آهوان' ، محمود جاجر مى r* ، ابوالفضل بخشى يور}

\author{
ا. دانشجوى دكترى تخصصى، كروه مشاوره، واحد بحنورد، دانشعاه آزاد اسلامى واحد بجنورد، بجنورد، ايران \\ ץ. استاديار، دكترى تخصصى، گروه مشاوره، واحد بجنورد، دانشعاه آزاد اسلامى واحد بجنورد، بجنورد، ايران
}

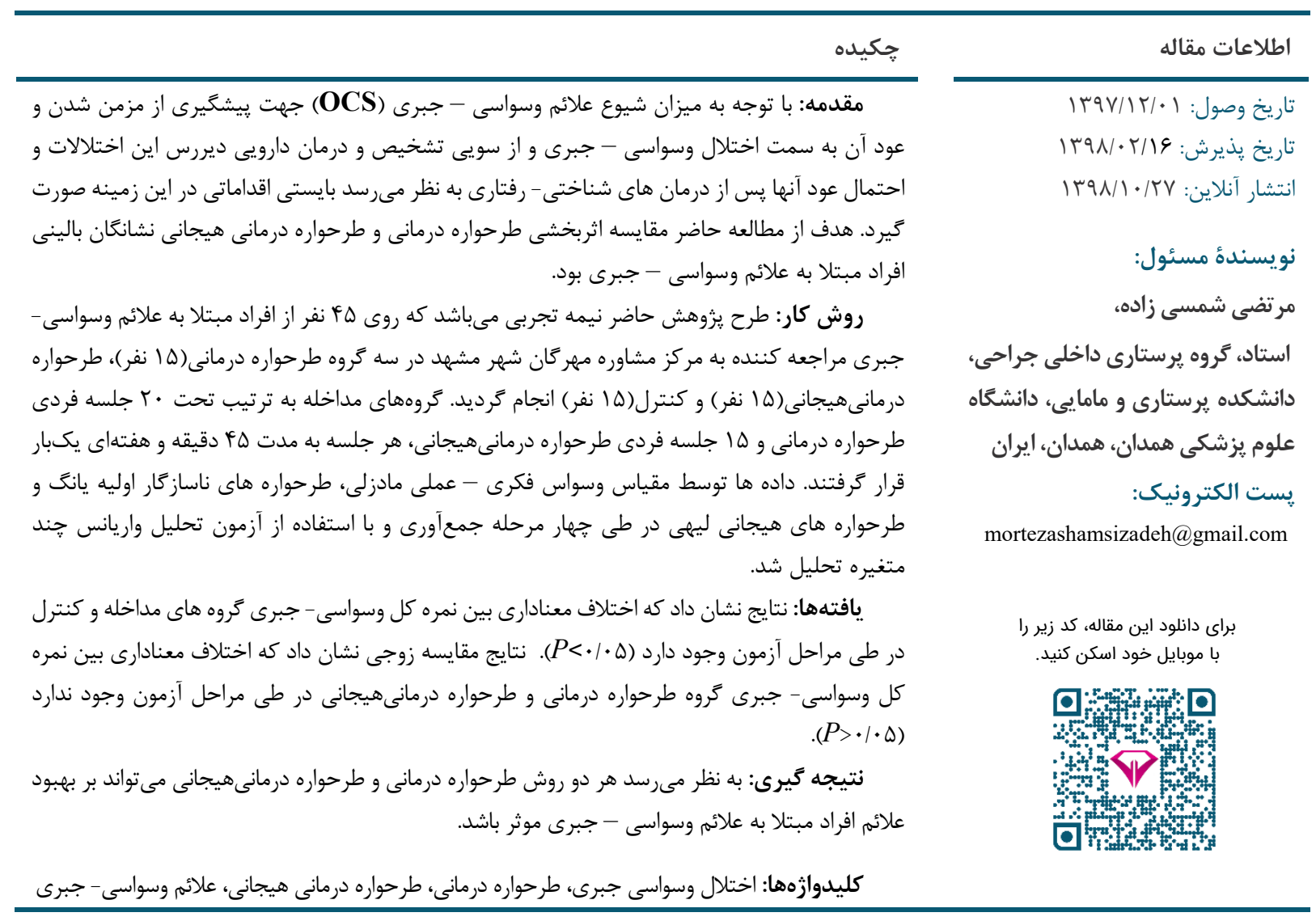

مقدمه

موجب كاهش كيفيت زندگى و اختلال عمكلرد شغلى، خانوادگى و زندگى اجتماعى گردد [ب]. اختلال وسواسى - جبرى با علائم وسواسى (افكار ناخواسته، مزاحم و تكرارى) يا جبرى (رفتارهاى اجبارى و تكرارى) يا هر

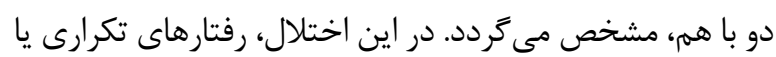

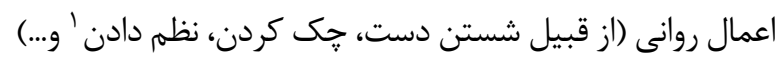

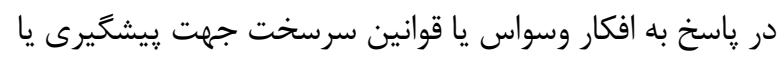
كاهش ديسترس ناشى از يك موقعيت يا رويداد تهديد كننده

1. Ordering
اختلال وسواسى- جبرى يكى از مسائل سلامت روان فراخيرى است كه حدود \&٪ عموم جمعيت را تحت تأثير قرار

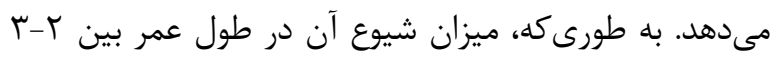
درصد برآورد شده است [ [ ]. اختلال وسواسى - جبرى (يس از اختلال افسردگى، سوء مصرف مواد و الكل و فوبى اجتماعى)

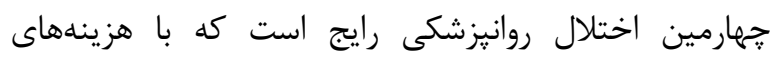
اقتصادى، اجتماعى و فردى زيادى همراه بوده [ب] و مىتواند 
درمان، سن شروع علائم و ... باشد. لذا، اكر جه رويكردهاى

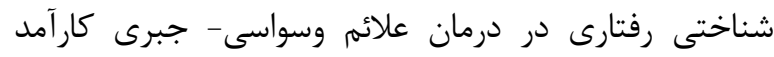

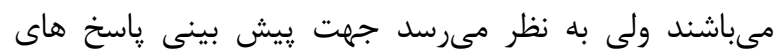

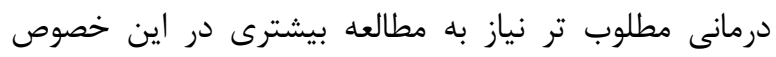

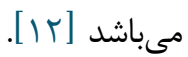
نتايج مطالعات، طرحوارههاى ناساز كار اوليه را به عنوان يكى

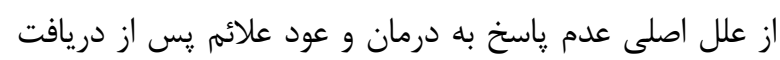

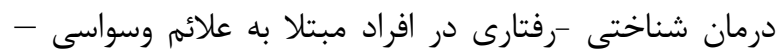

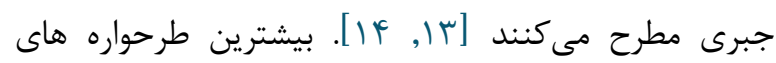

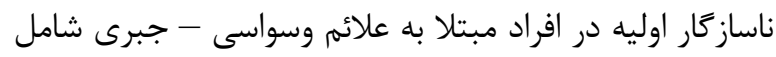

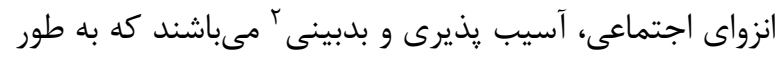

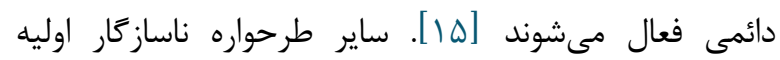

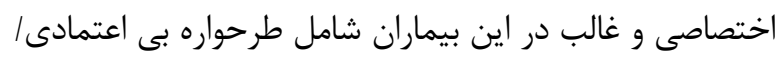

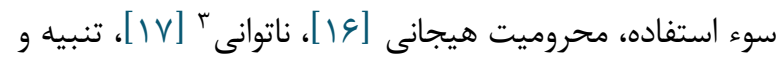

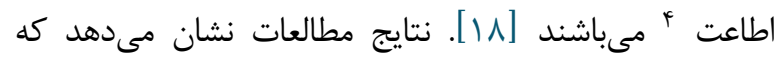
طرحوارههاى ناساز كار اوليه شدت علائم در اين بيماران را تحت

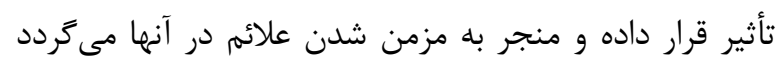

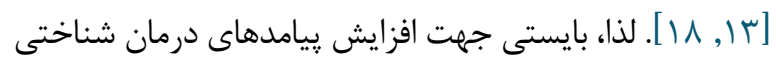

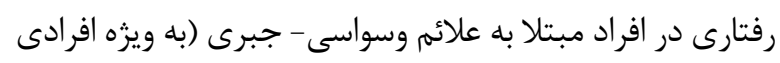

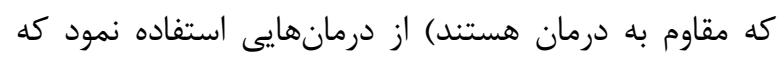

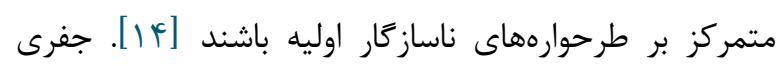

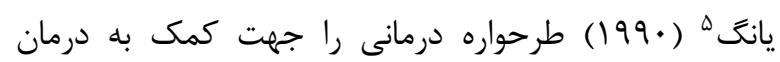

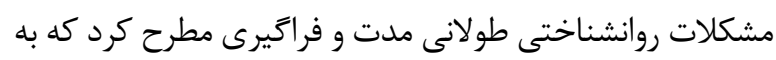

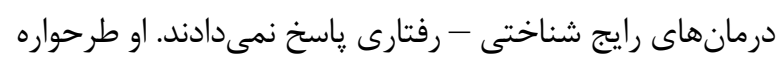

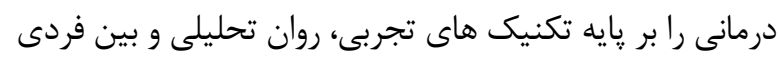

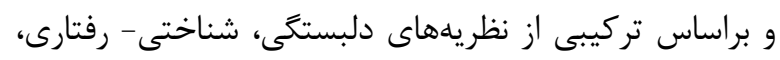

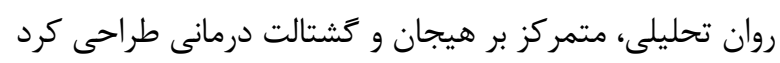

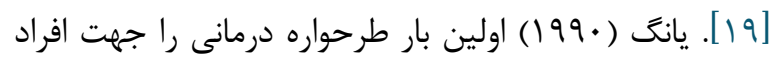

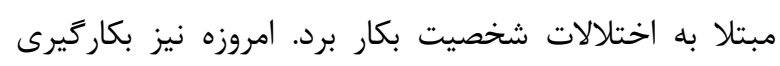

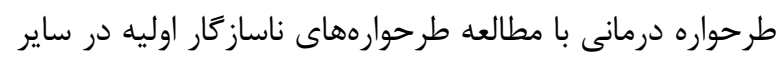

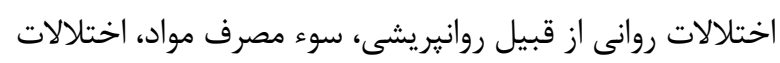

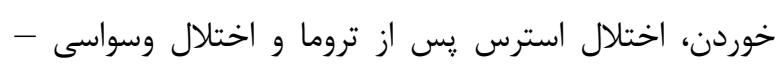

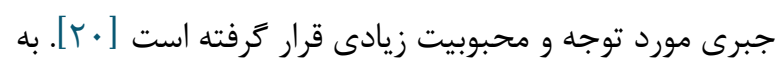

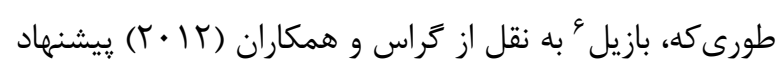

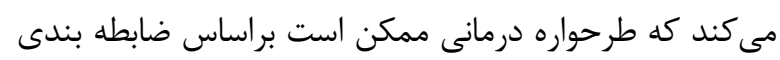

4. subjugation

5. Jeffrey Young

6. Basile

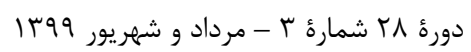

انجام مى گردد كه به وضوح غيرواقعى و افراطى است [F].]

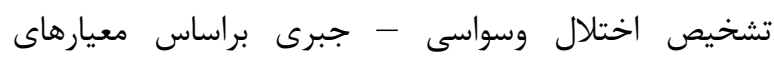

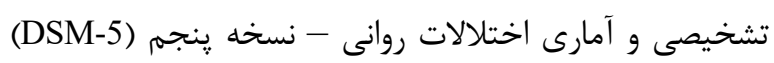

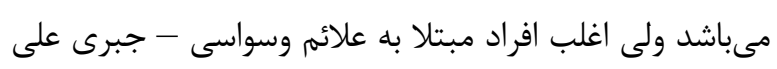

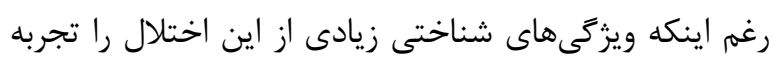

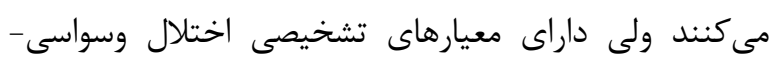

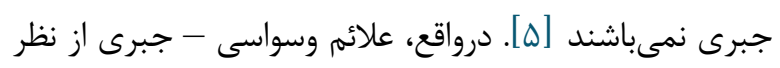

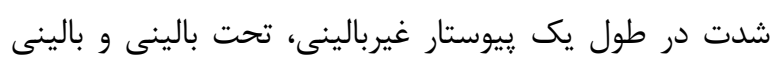

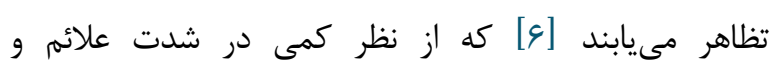

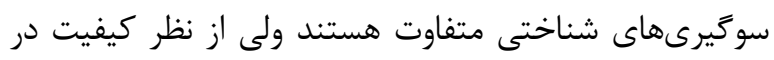

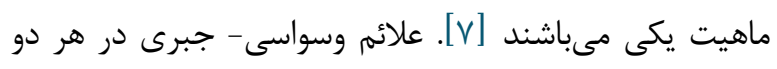

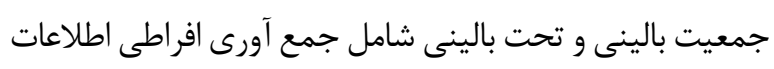

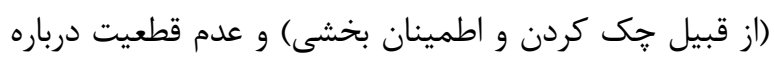

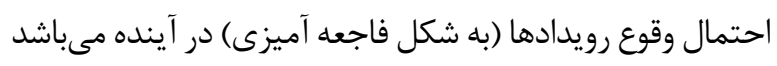

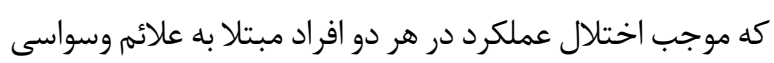
- جبرى و اختلال وسواسى جبرى مى كىردد [^].

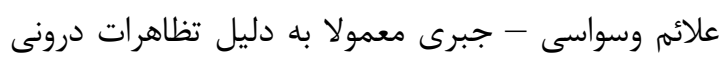

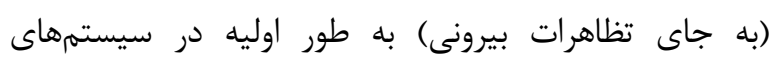

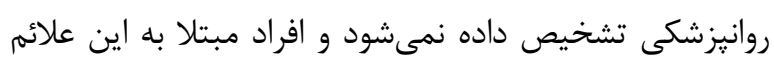

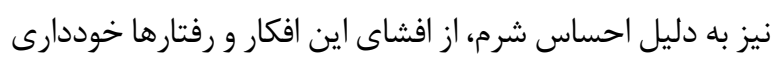

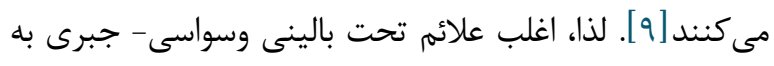

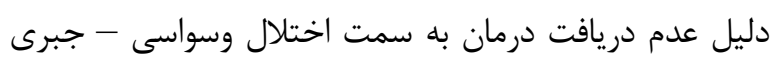

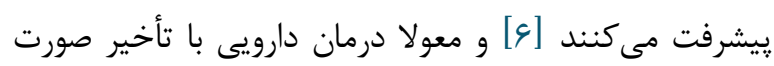

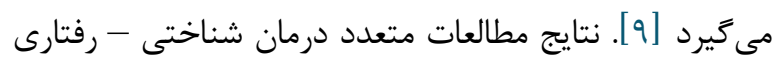

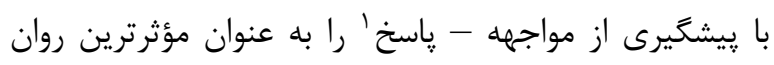

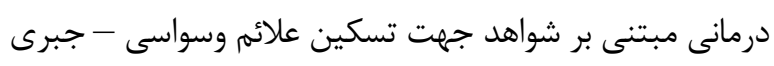

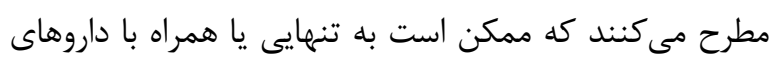

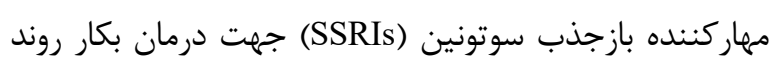

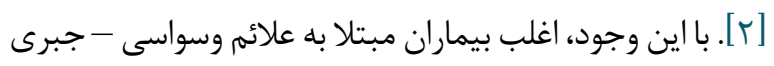

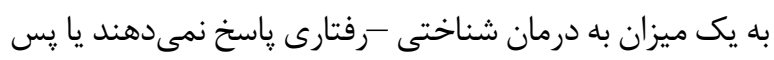

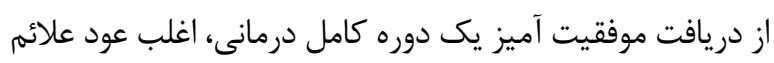

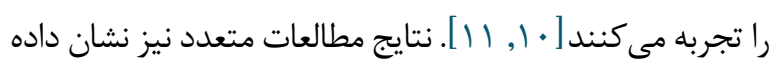
است كه اندازه اثر رويكردهاى شناختى -رفتارى در درمان علائم

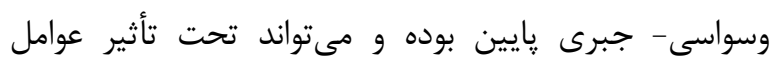

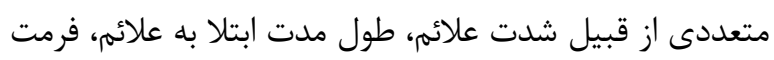

1. Exposure and Response Prevention

2. pessimism

3. failure 
مبتلا به علاثم وسواسى - جبرى غير بالينى و تحت بالينى انجام داد. اكثر مطالعات انجام شده در خصوص طرحواره درمانى و طرحواره درمانى هيجانى مربوط به بيماران مبتلا به اختلالات وسواسى -جبرى

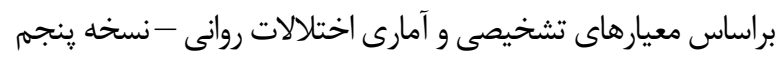
مىباشد كه اغلب مقاوم به درمان و مزمن شدهاند. در حالى كه، بهابه موارد غير بالينى و تحت بالينى و مقايسه اثربخشى اين دو مداخله در

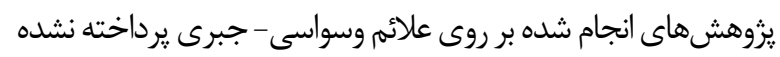

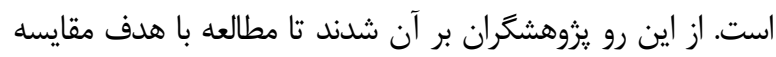

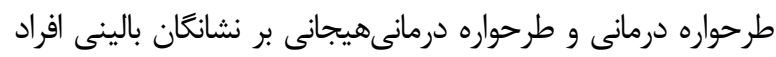
مبتلا به علائم وسواسى - جبرى بيردازند.

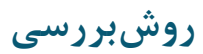

يزوهش حاضر از نوع نيمه تجربى با طرح بيش آزمون، پِ

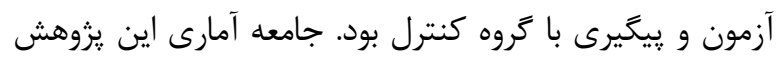

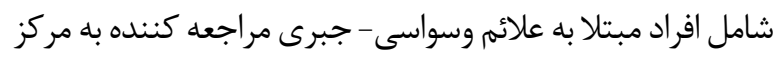

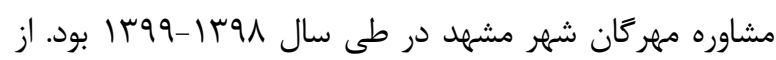

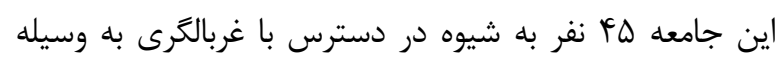

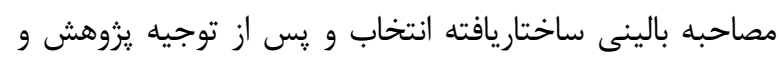

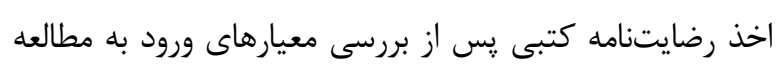

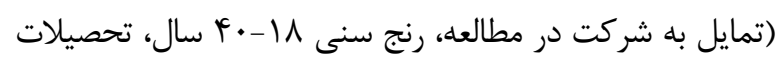

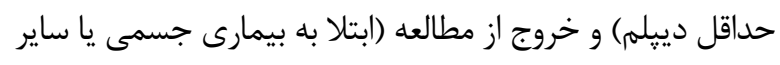

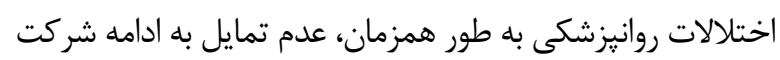

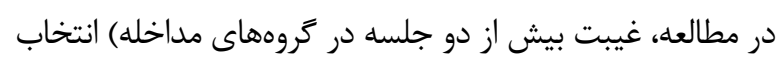

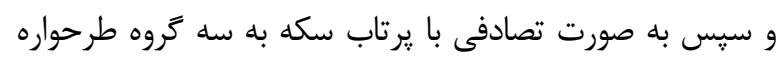

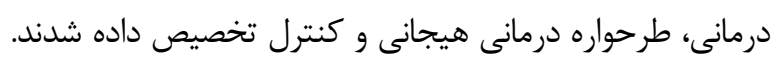

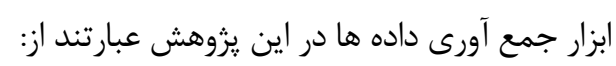

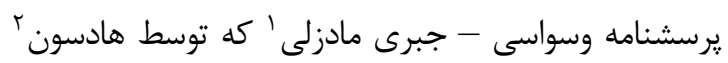

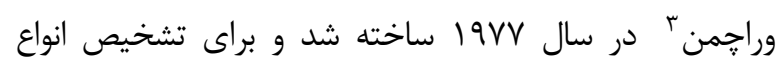

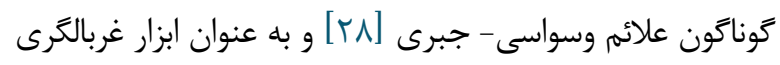

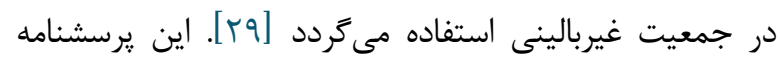

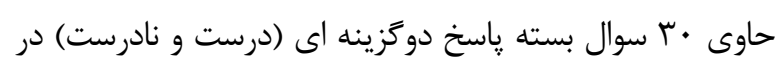
جهار زيرمقياس:

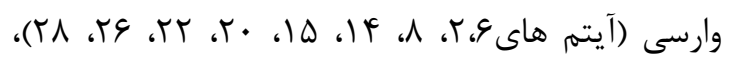

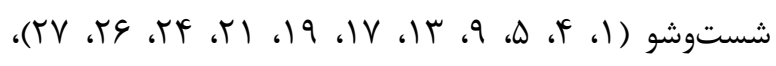

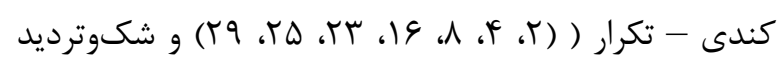

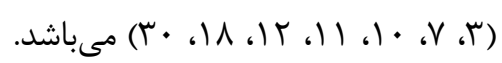

3. Rachman

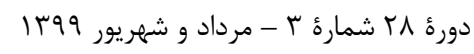

اختصاصى در اختلالات وسواسى - جبرى و به ويزه در اختلالات

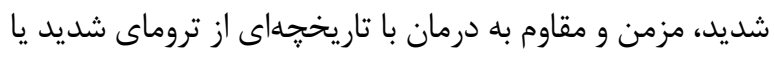

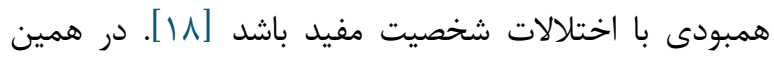

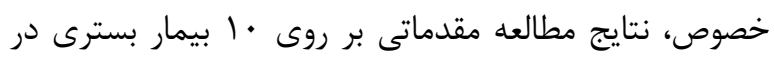

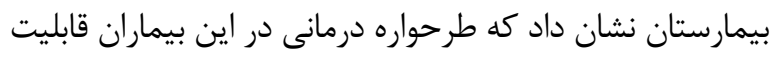

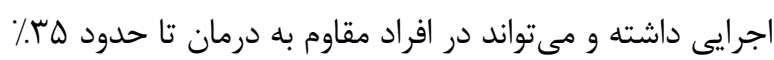

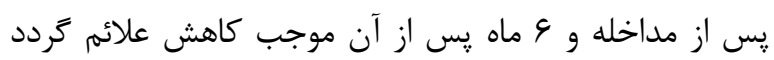

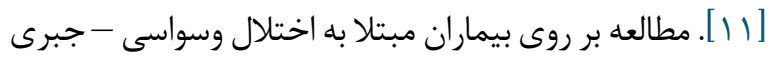

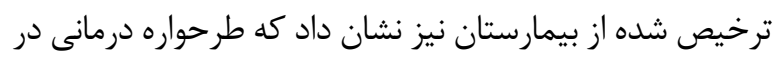

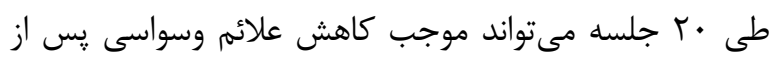

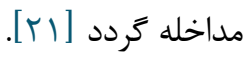
از سويى، علائم وسواسى - جبرى به دن دنبال افزايش

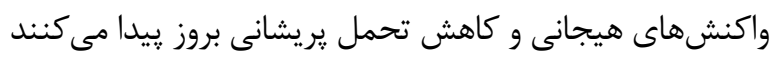

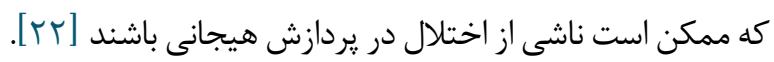

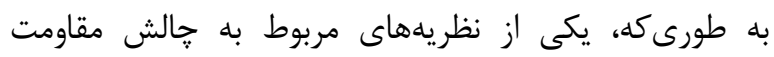

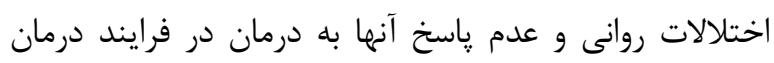

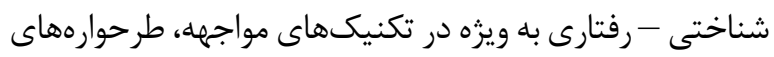

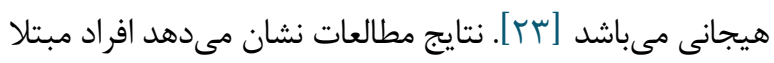

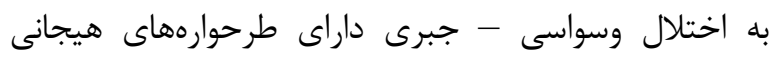

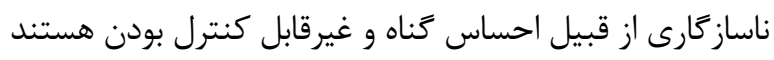

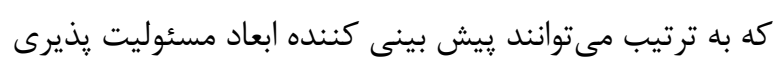

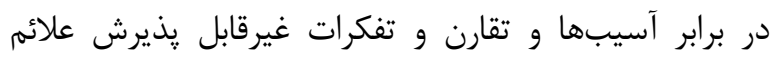

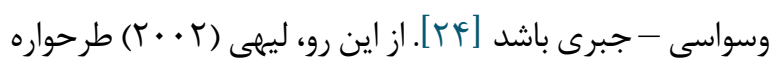

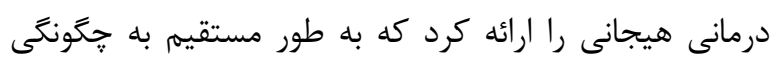

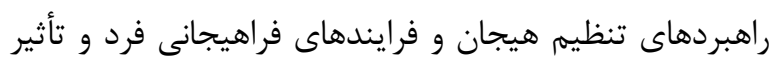

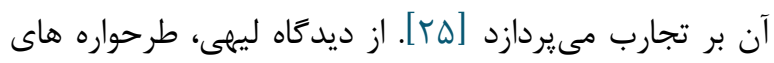

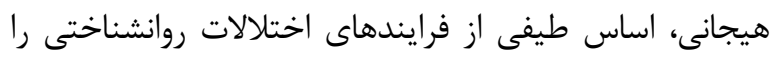

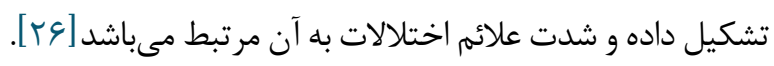

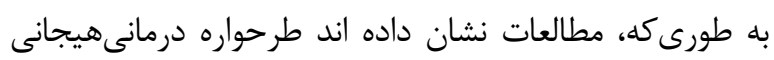

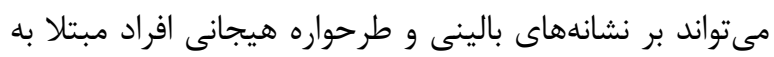

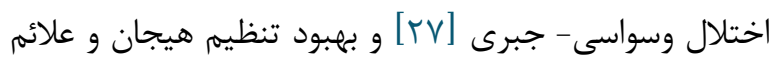
اضطراب اجتماعى مؤثر باشد [عr].

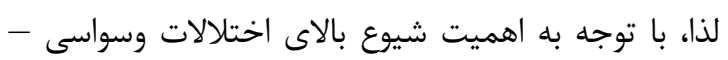

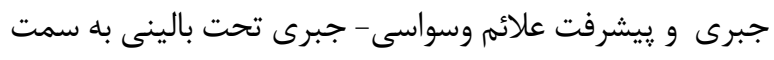

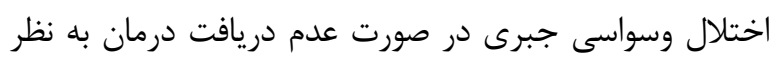

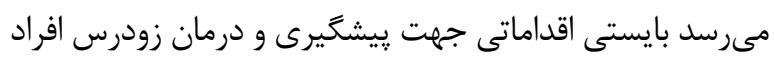


طى آن مطابقت زيادى بين ساختار نظرى خرده مقياسها و

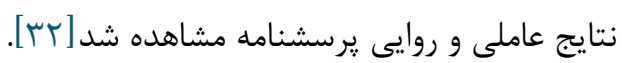

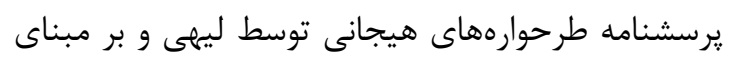

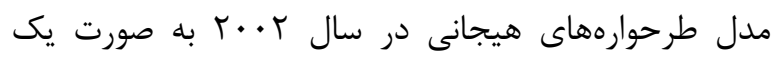

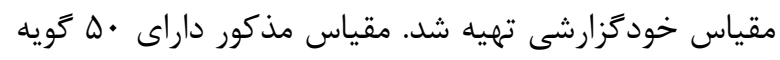

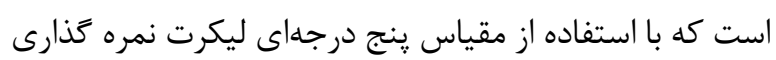

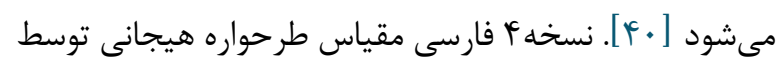

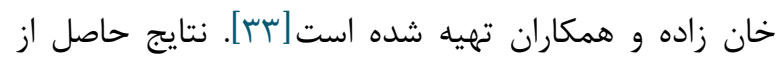

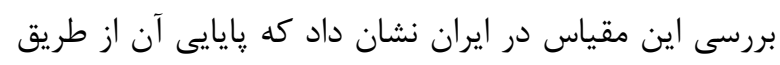

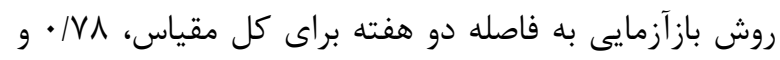

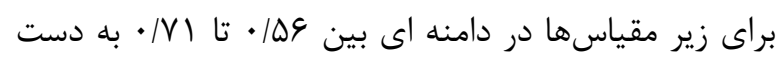

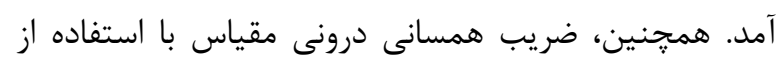

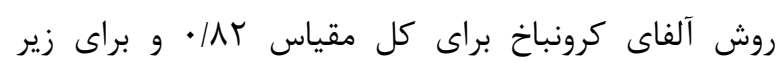

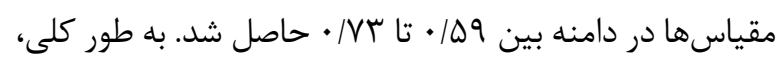

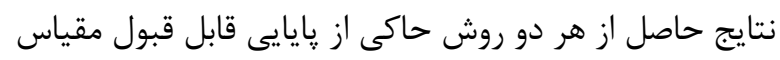

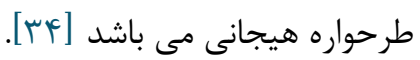

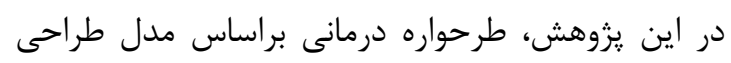

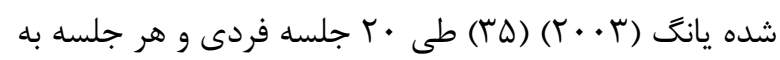

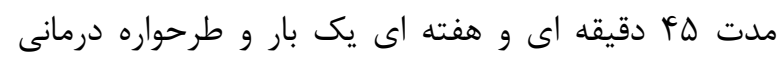

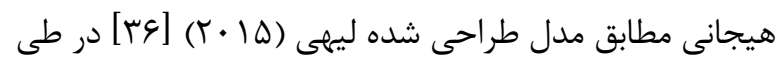

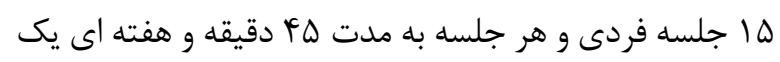

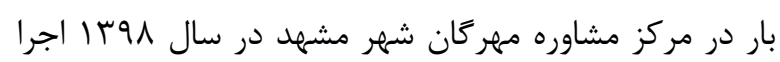

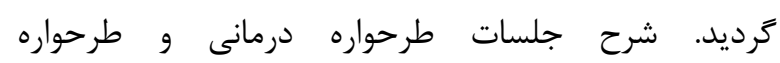
درمانى هيجانى به ترتيب در جدول آدلد آمده است.

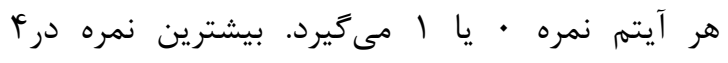

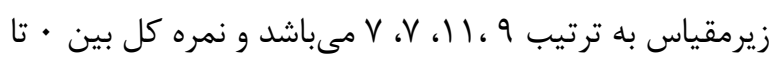

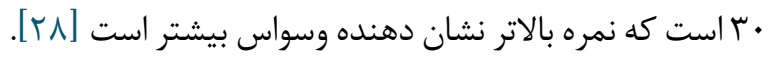

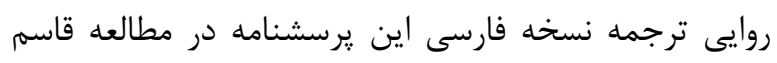

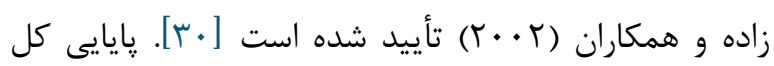

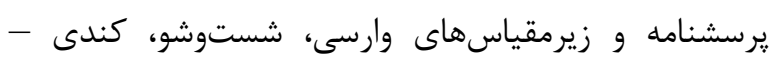

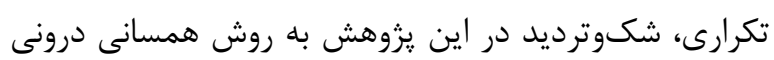

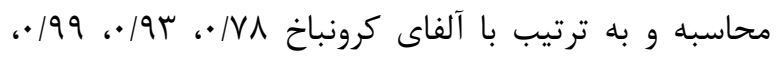

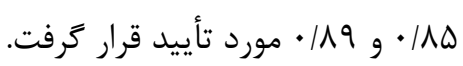

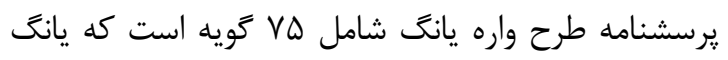

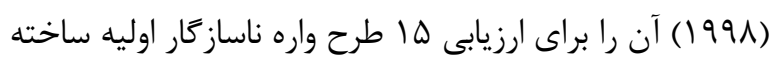

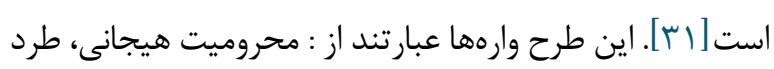

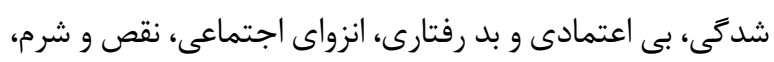

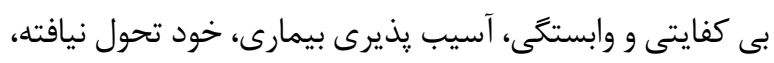

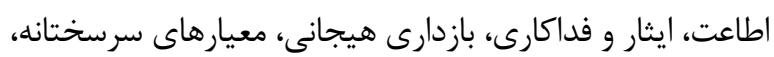
استحقاق، خود كنترلى ناكافى و شكست.

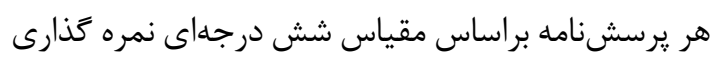

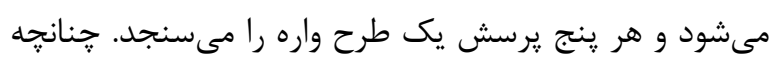

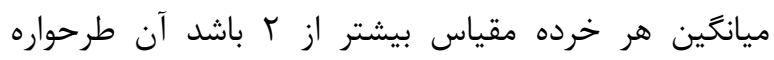

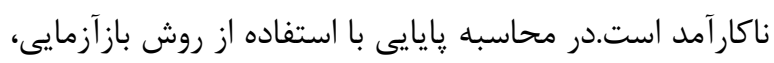

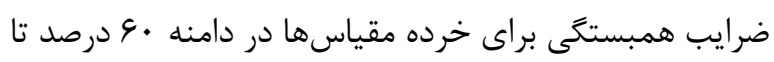

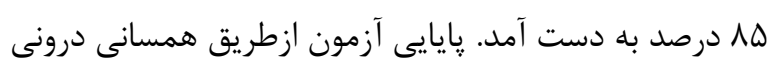

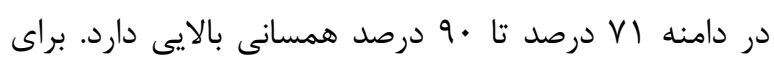

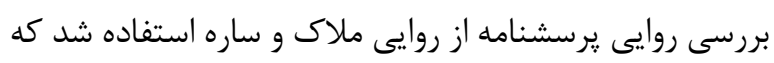

جدول ا. يروتكل جلسات

\section{طر حواره درمانى هيجانى}

ايجاد يك رابطه متقابل و برخوردار از تشريك مساعى، تبيين

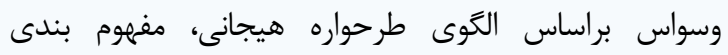
طرحوارههاى هيجانى، درجه بندى باورهاى هيجانى غلط،

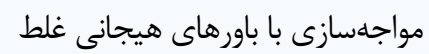

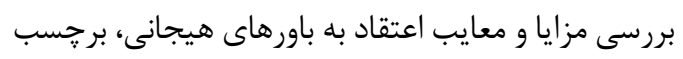

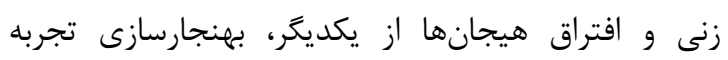
هيجانى، افزايش تحمل احساسات مختلط، استعاره انسان

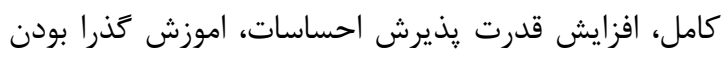

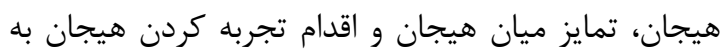

\section{طر حواره درمانى}

ايجاد يك رابطه متقابل و برخوردار

جلسات اتاس

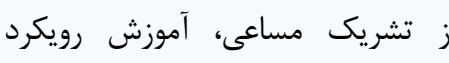

طرحواره درمانى، اخذ رضايت نامه آنه

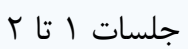
آكاهانه، ارايه آزمونهاى برماني، احثره سنجش مشكلات بيمار، ارزيابى

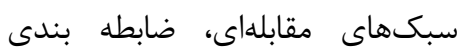

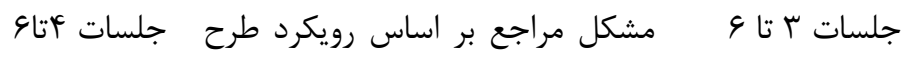

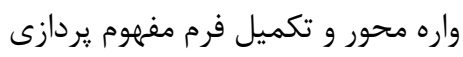

جلسات 
صورت موج، ازمايش رفتارى يِيشبينى عاطفى، درهم

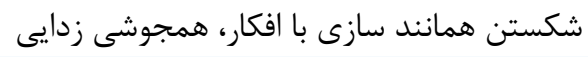

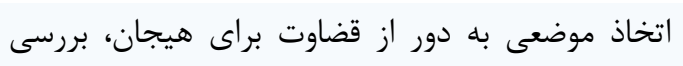
مقاومت در برابر اعتبار يابى شناسايى خاستخاههاى مختلف دور إنى

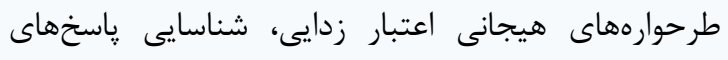

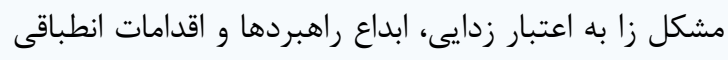

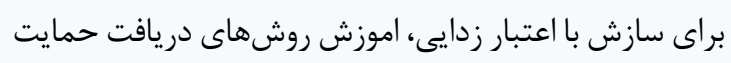
اجتماعى برى تقويت اكاهى هيجانى، القاى هيجان، فضاسازى هيجانى،

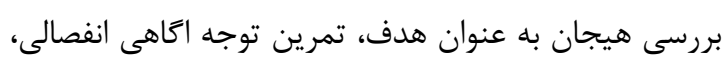
بالا رفتن از نردبان مفاهيه برتر، نقص كاميابى، شناسايى افكار

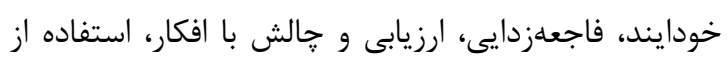
تكنيكهاى تعريف وازث، بررسى شواهد، وكيل مدافع، ايفاى

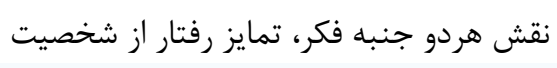

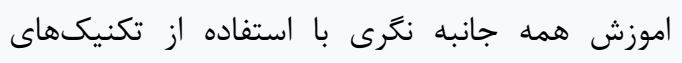

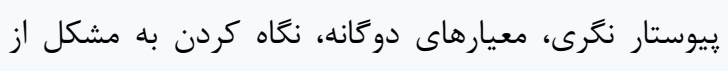

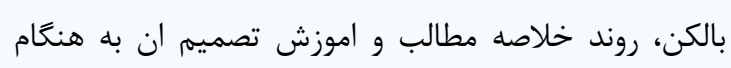

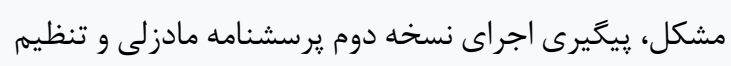

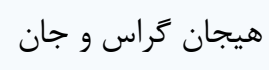

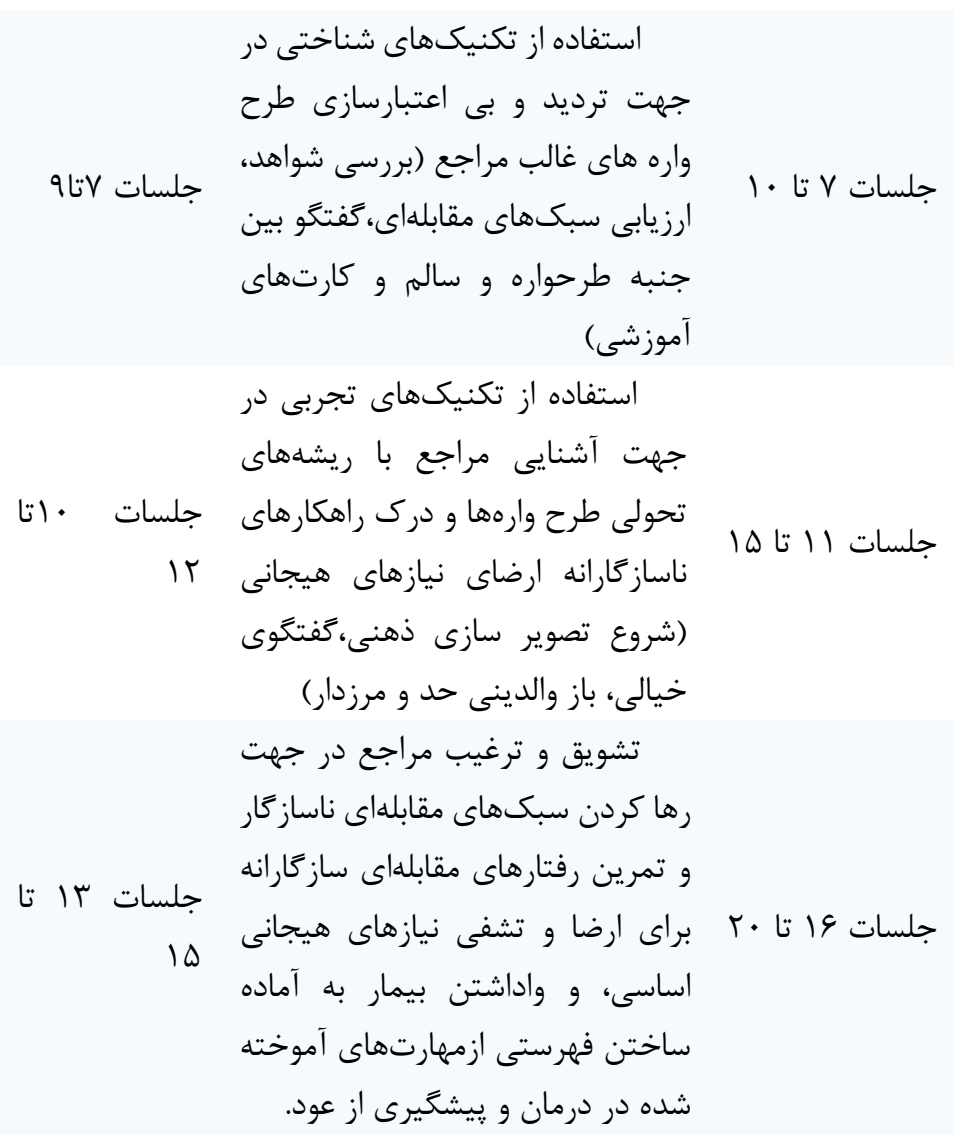

بافته ها

كروهها، ابتدا مفروضههاى زيربنايى تحليل واريانس جند متغير

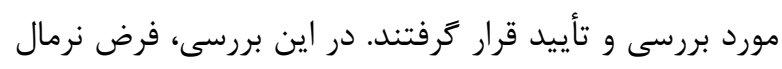

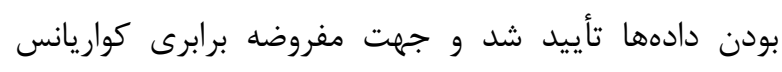
متغيرهاى وابسته در تمامى سطح متغير مستقل از آزمون

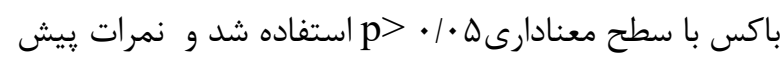
آزمون به عنوان متغير كواريت ' در نظر گرفته شدند. محاسبه

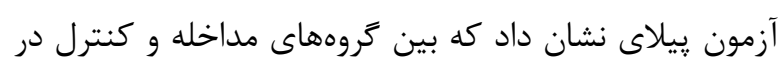
سطح معنادارى ه • / > p تفاوت معنادارى وجود دارد.
يزوهش حاضر بر روى هأ نفر از افراد مبتلا به علائم وسواسى - جبرى در سه گروه طرحواره درمانى (ها نفر)، طرحواره درمانى هيجانى (ها نفر) و كنترل (ها (ه نفر) انجام

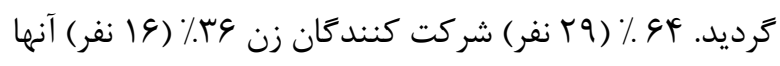

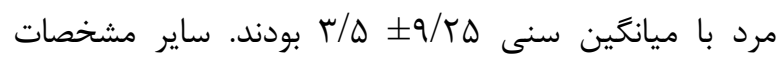
جمعيتى افراد مبتلا به علائم وسواسى - جبرى شركت كنين منده در مطالعه حاضر در جدول r آمده است.

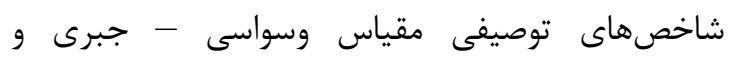
زيرمقياسهاى آن در جدول ب آمده است. جهت مقايسه نمرات 
جدول r. مشخصات جمعيت شناختى سه كروه مورد يزوهش

\begin{tabular}{|c|c|c|c|c|}
\hline كنترل & طر حواره درمانى & طر حواره درمانى & \multirow[t]{3}{*}{ متغير } & \multirow{11}{*}{ جنسيت } \\
\hline Q ا نفر = & Q 1 نفر = & ه = ا نفر & & \\
\hline $\mathrm{n}(\%)$ & $\mathrm{n}(\%)$ & $\mathrm{n}(\%)$ & & \\
\hline$\|(V T)$ & $9(9 \cdot)$ & $9(9 \cdot)$ & 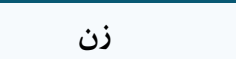 & \\
\hline$F(T V)$ & $\varphi(f \cdot)$ & $\varphi(f \cdot)$ & 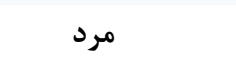 & \\
\hline$\wedge(\Delta \Gamma)$ & $V(q V)$ & $V(F V)$ & ديبلم & \\
\hline$r(I r)$ & $r(r \cdot)$ & $r(r \cdot)$ & فوق دييلم & \\
\hline$F(\Gamma \varphi)$ & $\Delta(r)$ & $\Delta(r \mu)$ & ل ل ل ل ل & \\
\hline $1(\wedge)$ & $\cdot(\cdot / \cdot)$ & $\cdot(\cdot / \cdot)$ & فوق ليسانس & \\
\hline ميانكين ( انحراف معيار ) & ميانكَين ( انحراف معيار ) & ميانكَين ( انحراف معيار ) & \multirow{2}{*}{ سن } & \\
\hline$(\Delta / \varnothing) \Gamma \Delta / q$ & (द) $T Y / \Delta$ & $(\Psi / Q) Y \Psi / V$ & & \\
\hline
\end{tabular}

جدئول r. ميانغين و انحراف معيار نمرات مقياس وسواسى - جبرى و زيرمقياس هاى مربوطه در طى مراحل آزمون

\begin{tabular}{|c|c|c|c|c|c|c|c|c|c|c|c|c|}
\hline \multicolumn{4}{|c|}{ كنترل } & \multicolumn{4}{|c|}{ طر حواره درمانى هيجانى } & \multicolumn{4}{|c|}{ طر حواره درمانى } & \\
\hline بعدي ازيَيرى & بيكد ازيكيرى & آزمون & آزمون & بي بعد از & بيكد ازيرى & آزمون & آزمون & بعد ازيره سه & بيكيَيرى & آزمون & آزمون & متغير \\
\hline ميانكين & ميانكين & ميانكين & ميانكين & ميانكين & ميانكين & ميانكَين & ميانكَين & ميانكَين & ميانكين & ميانكَين & ميانكين & \\
\hline 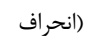 & (انحراف & (انحراف & (انحراف & (انحراف & (انحراف & (انحراف & (انحراف & (انحراف & (انحراف & (انحراف & (انحراف & \\
\hline معيار) & معيار) & معيار) & معيار) & معيار) & معيار) & معيار) & معيار) & معيار) & معيار) & معيار) & معيار) & \\
\hline$V / \Lambda$ & $V / v$ & $V / \Lambda$ & V/q & $r / 1$ & $r / 1$ & 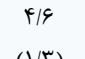 & V/I & $r / \Delta$ & $r / 9$ & $r / /$ & $\begin{array}{l}r \\
\text { r }\end{array}$ & بازبينى \\
\hline $\begin{array}{c}(\cdot \pi) \\
\wedge\end{array}$ & $\stackrel{(\cdot \pi)}{\wedge}$ & $\begin{array}{l}(\pi /) \\
V / 9\end{array}$ & $\begin{array}{l}\cdot(\pi) \\
V / 9\end{array}$ & $\begin{array}{l}(I N) \\
F / T\end{array}$ & $\begin{array}{l}(1 / 4) \\
r / \Delta\end{array}$ & $\Delta / f$ & V/a & $r / \Delta$ & $r / 9$ & $r$ & $\wedge$ & \\
\hline$(\cdot \pi)$ & (.) & $(\cdot / \mu)$ & $(\cdot / \Delta)$ & $(\Gamma / 4)$ & $(\tau / \varphi)$ & $(\pi / \%)$ & (1) & $(. / 9)$ & $(\cdot / 9)$ & $(1 / \pi)$ & $(\cdot / 9)$ & ستسن \\
\hline$r / \Delta$ & $r / \Delta$ & $r / 4$ & $r / 1$ & $r / \%$ & $r / 1$ & $r / 4$ & $r / 1$ & $r / 4$ & r/9 & $r / r$ & $r / \Lambda$ & 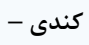 \\
\hline$(.19)$ & $(\cdot / v)$ & $(\cdot / v)$ & $(\cdot / \pi)$ & $(1 / \Lambda)$ & $(1 / v)$ & $(1 / 9)$ & $(\cdot / \Lambda)$ & $\left(1 / f^{4}\right)$ & $(1 / \Gamma)$ & $(\cdot / 9)$ & $(1 / \wedge)$ & تكرار \\
\hline $9 / \Delta$ & $9 / 9$ & 919 & $9 \pi$ & $r / 9$ & $r / \Delta$ & $r / N$ & $\Delta / V$ & 1/9 & r & $r / r$ & $\Delta / r$ & ترديد - \\
\hline$(\cdot / v)$ & $(\cdot / \Lambda)$ & $(\cdot / V)$ & $(1 / \pi)$ & $(1 / 9)$ & $(1 / \Lambda)$ & $(1 / 9)$ & $(.19)$ & $(\cdot / \Lambda)$ & $(\cdot / 9)$ & $(\cdot / v)$ & (r) & شناسى وطي \\
\hline TAIT & ra/T & rQ/9 & $r F / q$ & $15 / 9$ & $1 \% / T$ & 19 & $T \& / N$ & $9 / 5$ & $9 / \Delta$ & $11 / \pi$ & $r \Delta / \Delta$ & " نمره \\
\hline$(1 / r)$ & $(1 / r)$ & $(1 / \Delta)$ & $(1 / 4)$ & $(\xi / 4)$ & $(\varepsilon / 4)$ & $(\Delta / f)$ & $(I / r)$ & $(\Gamma / \Delta)$ & $(\pi / \varphi)$ & $(r / 1)$ & $(1 / 1)$ & كوسواس \\
\hline
\end{tabular}

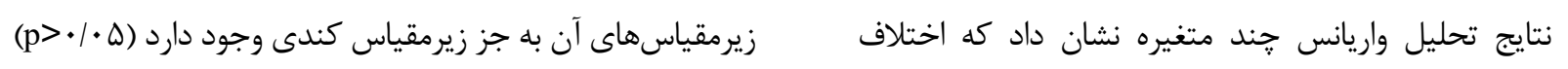

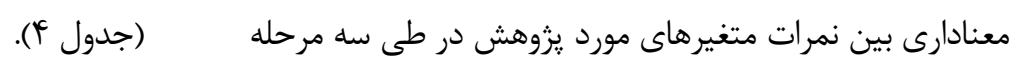

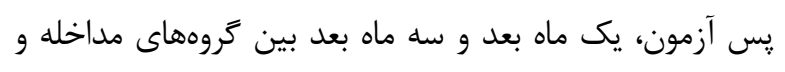

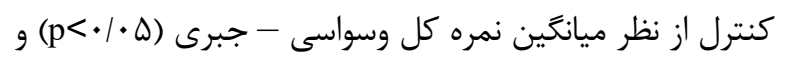


جدول \&: نتايج تحليل واريانس جند متغيرى در سه تروه يخوهش

\begin{tabular}{|c|c|c|c|c|c|c|c|c|c|c|c|c|}
\hline \multicolumn{4}{|c|}{ بيخيرى بعد از سه ماه } & \multicolumn{4}{|c|}{ بيَيرى بعد از يكماه } & \multicolumn{4}{|c|}{ يس آزمون } & \multirow[b]{2}{*}{ متغير وابسته } \\
\hline ضريب & معنادارى & آزادى درجه & $\mathrm{F}$ & ضريب بتا & معنادارى & آزادى درجه & $\mathrm{F}$ & ضريب بتا & معنادارى & آزادى درجه & $\mathbf{F}$ & \\
\hline$\cdot / V$ & $\cdot 1 \cdot \cdot 1$ & 1 & $r \& / D$ & $\cdot / V$ & $\cdot|\cdot|$ & 1 & $r Q / 1$ & $\cdot / V$ & $\cdot|\cdot|$ & 1 & $r F / l$ & بازبينى \\
\hline$\cdot / V$ & $\cdot|\cdot|$ & 1 & $r \wedge / \Delta$ & $\cdot / V$ & $\cdot|\cdot|$ & 1 & $r \Delta / \zeta$ &. $\mid 9 T$ & $\cdot \mid \cdot \cdot 1$ & 1 & $19 / 0$ & شستن \\
\hline$\cdot / 4$ & $\cdot 1 \cdot \Lambda$ & 1 & $\Delta / \Delta$ & $\cdot / T$ & .111 & 1 & $r / \mathcal{F}$ & $\cdot|\Delta|$ & $\cdot \pi$. & 1 & $1 / 1$ & كندى - تكرار \\
\hline$\cdot / V$ & $\cdot 1 \cdot \cdot 1$ & 1 & $r \mid r$ & $\cdot / V$ & $\cdot 1 \cdot \cdot 1$ & 1 & $r \Delta / 1$ & $\cdot / V$ & $\cdot / \cdots 1$ & 1 & $r q / r$ & شناسى \\
\hline$\cdot \mid \mathrm{A}$ & $\cdot 1 \cdot \cdot 1$ & 1 & $r \Delta / l$ & $\cdot \mid \Lambda$ & $\cdot 1 \cdot \cdot 1$ & 1 & $M F / F$ & $\cdot / 1$ & $\cdot \mid \cdots 1$ & 1 & $r \Delta / \Delta$ & *نمره كلى \\
\hline
\end{tabular}

نتايج آزمون تعقيبى بون فرونى در مقايسه دو به دو كروههاى مداخله و كنترل در جدول ه آمده است.

جدول ه. نتايج مقايسه روجى تروهها در متغيرهاى وابسته يزوهش با استفاده از آزمون بون فرونى

\begin{tabular}{|c|c|c|c|}
\hline بيگيرى بعد از سه ماه & بيگيرى بعد از يكماه & يس آزمون & متغير وابسته \\
\hline$\cdot 1 \cdot \cdot 1$ & $\cdot|\cdot|$ & $\cdot \mid \cdot \cdot 1$ & بازبينى \\
\hline$\cdot \mid \cdots 1$ & $\cdot|\cdot|$ & $\cdot|\cdot|$ & شستشو \\
\hline$\cdot|r|$ & $\cdot / \mu$ & 1 & كندى - تكرار \\
\hline$\cdot 1 \cdot \cdot 1$ & $\cdot 1 \cdot \cdot 1$ & $\cdot 1 \cdot \cdot 1$ & ترديد - وظيفه شناسى \\
\hline$\cdot 1 \cdot \cdot 1$ & $\cdot 1 \cdot \cdot 1$ & $\cdot 1 \cdot \cdot 1$ & نمره كلى وسواس \\
\hline
\end{tabular}

\section{بحث و نتيجه تيرى}

از مداخله و يك ماه بعد مؤثر بودند ولى در مرحله بيگيرى طرحواره درمانى بر كاهش اين زيرمقياس مؤثرتر بود كه

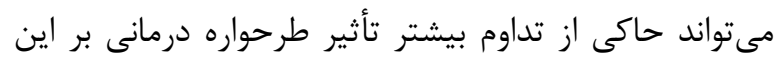

$$
\text { زيرمقياس باشد. }
$$

اين مطالعه براى اولين بار به مقايسه دو روش درماندى دمانى

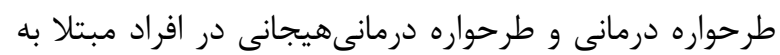
علائم وسواسى- جبرى مىيردازد. نتايج مطالعات حاضر با نتايج مطالعات قبلى مبنى بر تأثير طرحواره درمانى هيجانى بر

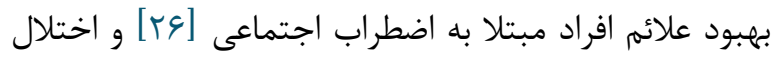

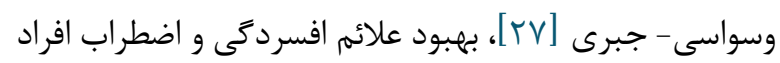

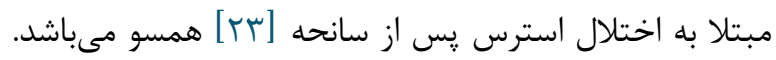

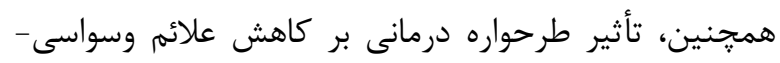
جبرى در افراد مبتلا به اختلال وسواسىى - جبرى در مطالعه يايلوت [111]، تأييد كننده نتايج مطالعه حاضر است. در ايران،
هدف از انجام مطالعه حاضر مقايسه اثربخشى طرحواره درمانى با طرحواره درمانى هيجانى بر نشانگان بالينى افراد مبتلا

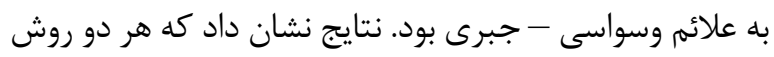
طرحواره درمانى و طرحواره درمانى هيجانى مى تواند بر نشانعان

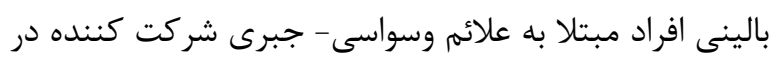
مطالعه حاضر مؤثر باشد ولى هيج يك از روشهاى بـى درمانى، بر زيرمقياس كندى مؤثر نبود. از سويى، در مقايسه بين دو روش مئ

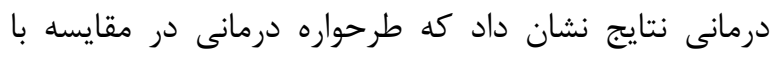

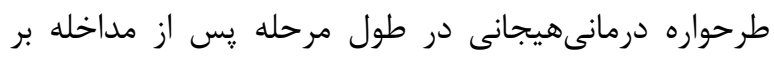
كاهش ميانخين نمره كل مقياس وسواسى - جبرى و و زيرمقياس شستشو مؤثرتر بود ولى در مراحل ييگيرى بين آنها تفاوت معنادارى وجود نداشت كه حاكى از تأثير يكسان هر دو موري روش در درازمدت باشد. در عوض، هر دو روش درمانى بر كاهش ميانگين نمره زيرمقياس شك و ترديد در مرحله يس 
روانى از قبيل وسواسى - جبرى در ابعاد مختلف بكاهد و منجر

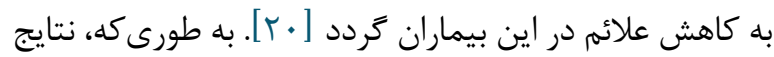
مطالعه حاضر نيز نشان مىدهد كه طرحواره درمانى مى تواند

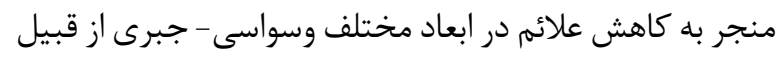
بازبينى، شستشو، ترديد- وظيفه شناسى در افراد مبتلا به الها علائم وسواسى - جبرى كردد. بيماران مبتلا به علائم وسواسى

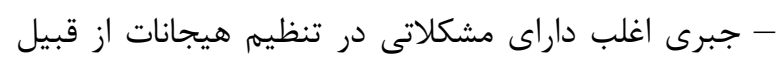

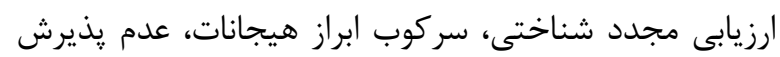

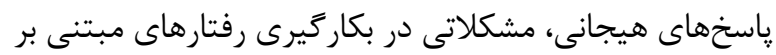

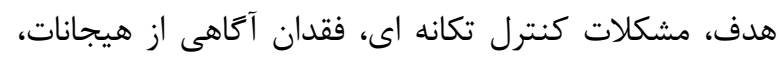
محدوديت دستيابى به استراتزىهاى تنظيم هيجان و فقدان واضح هيجانات مىباشند كه با ابعاد مختلف علائم وسواسى

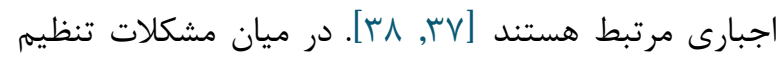

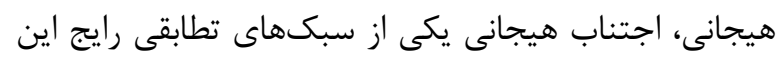
بيمار ان مىباشد كه مىتواند شدت علائم بيمار ان را تحت تأثانير إنى

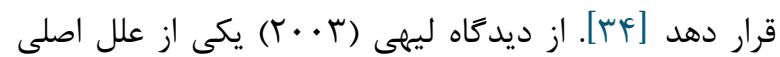
علائم اين بيماران مىتواند طرحوارههاى هيجانى باشد كه آنها

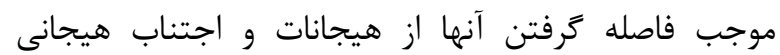
مىشود. به طورى كه، يكى از تكنيكهاى اصلى درمان علائم

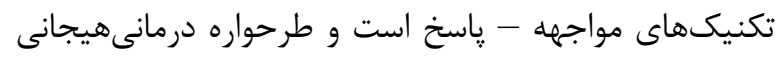

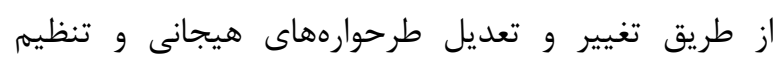
هيجانات به درمان علائم اختلالاتى از قبيل وسواسى - جبرى

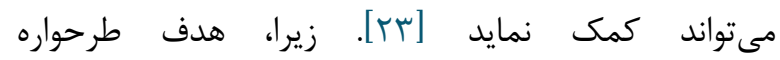

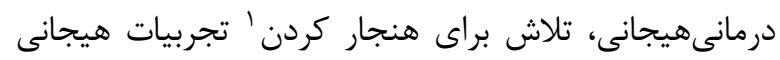

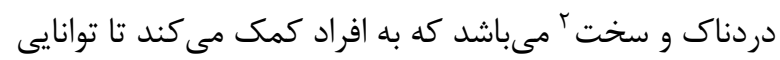

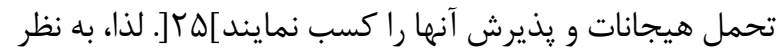

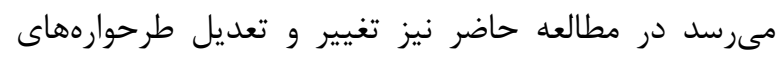
هيجانى به طور غيرمستقيم مىتواند موجب كاهش على علائم نعدير

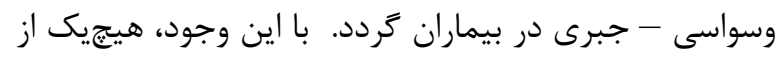
روشهاى درمانى بر زيرمقياس كندى مؤثر نبود. زيرمقياس

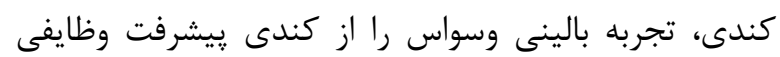
نشان مىدهد كه به دليل رفتارهاى تكرارى ناشى از وسواس باس

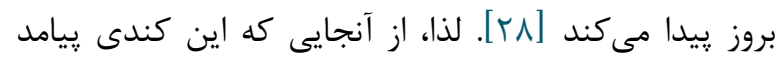

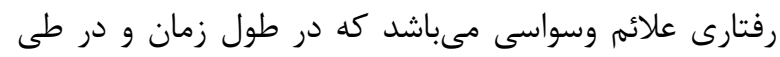

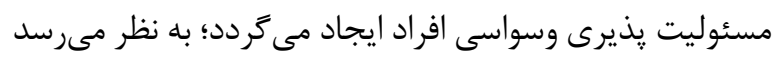

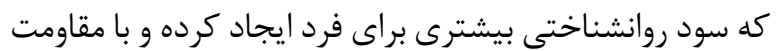

2. Painful and difficult
مطالعهاى بر روى بيماران مبتلا به اختلال وسواسى - جبرى ترخيص شده از بيمارستان انجام شده بود كه نتايج آن نيز

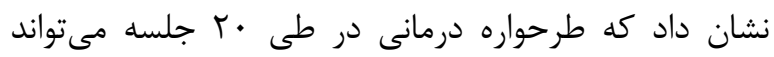

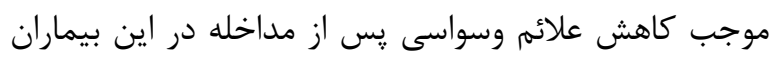

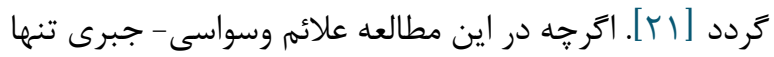
در يك مرحله و يس از مداخله (در مقايسه با مطالعه حاضر كه

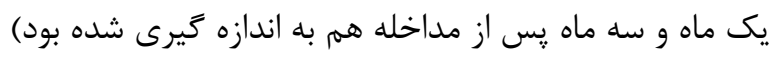
مورد مطالعه قرار گرفته بودند ولى نتايج آن تأييد كننده و همسو با نتايج مطالعه حاضر مىباشد.

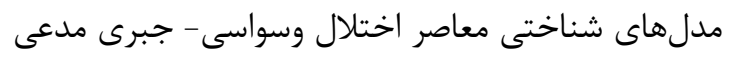

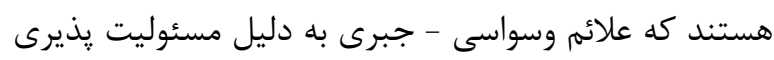
فردى و ميزان تهديد ناشى از موقعيتها، احساسات و رويدادهاى روانى توسعه يافته و حفظ مى شوند. اغلب افراد

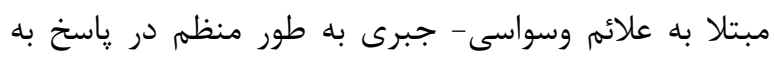

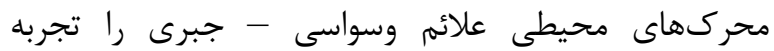
مى كنند. بدين صورت كه، آنها متعاقب ارزيابىهاى مدئى منفى

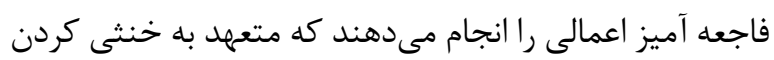

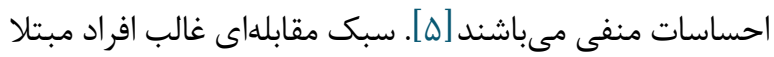
به علائم وسواسى - جبرى رفتارهاى اجتنابى و سبك والدينى

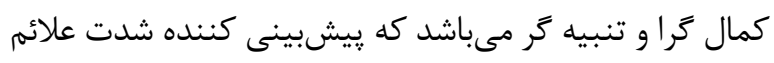

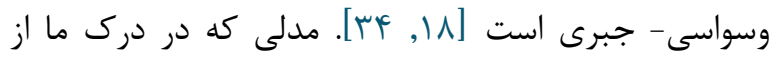
ارتباط ميان تجربيات زندگى كودكى و آسيب شناسى روانى مشاركت دارد، تئورى طرحواره است. مطابق اين تئورى،

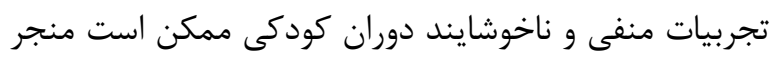

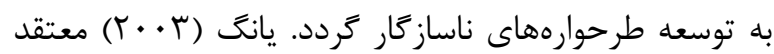

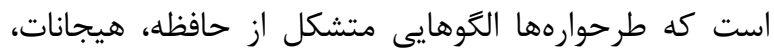

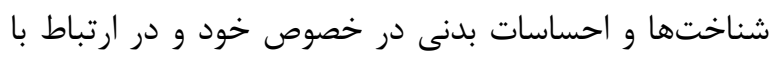
ديخران هستند و مىتوانند علت بسيارى از علائم اختلالات

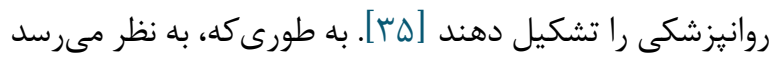

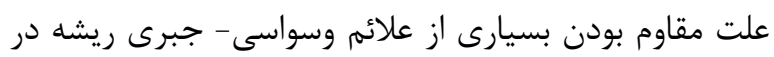

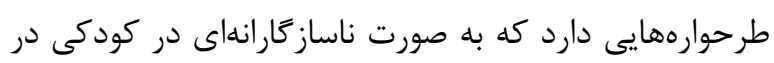
افراد شكل كرفته و در بزر گسالى به صورت علائم وسواسى جبرى به طور دائم فعال مىشود و علائم را به سمت مزمن

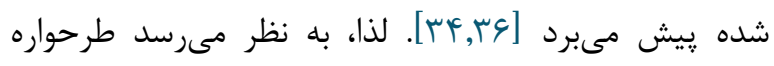
درمانى به طور غير مستقيم از طريق تغيير و اصلاح طرحوارههاى ناساز كار اوليه مىتواند از شدت علائم اختلالات

1 Normalise

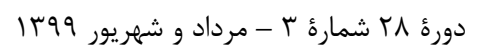


مئاشد و از دانشعاه آزاد

اسلامى واحد بجنورد جهت تصويب طرح يزوهشى حاضر و تمامى افراد شركت كننده در اين مطالعه به خاطر صبر و

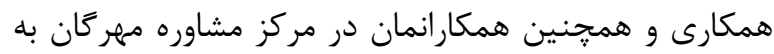
دليل همكارى صميمانه، تشكر و قدردانى مى كنيم.

$$
\text { تعارض در منافع }
$$

بين نويسندگان هيجگَنه تعارضى در منافع وجود ندارد

منابع مالى

منابع مالى اين مطالعه توسط نويسندًان تامين شده است

\section{References}

1. Nazeer A, Latif F, Mondal A, Azeem MW, Greydanus DE. Obsessive-compulsive disorder in children and adolescents: epidemiology, diagnosis and management. Translational Pediatrics. 2020;9(Suppl 1):S76. [DOI:10.21037/tp.2019.10.02] [PMID] [PMCID]

2. Hirschtritt ME, Bloch MH, Mathews CA. Obsessive-compulsive disorder: advances in diagnosis and treatment. Jama. 2017;317(13):135867. [DOI:10.1001/jama.2017.2200] [PMID]

3. Rickelt J, Viechtbauer W, Lieverse R, Overbeek T, van Balkom AJ, van Oppen $P$, et al. The relation between depressive and obsessive-compulsive symptoms in obsessive-compulsive disorder: results from a large, naturalistic follow-up study. Journal of affective disorders. 2016;203:241-7. [DOI:10.1016/j.jad.2016.06.009] [PMID]

4. Smit DJ, Cath D, Zilhão NR, Ip HF, Denys D, den Braber A, et al. Genetic meta-analysis of obsessivecompulsive disorder and self-report compulsive symptoms. American Journal of Medical Genetics Part B: Neuropsychiatric Genetics. 2020;183(4):208-16. [DOI:10.1002/ajmg.b.32777] [PMID] [PMCID]

5. Bradley MC, Hanna D, Wilson P, Scott G, Quinn P, Dyer KF. Obsessive-compulsive symptoms and attentional bias: An eye-tracking methodology. Journal of behavior therapy and experimental psychiatry. 2016;50:303-8 [DOI:10.1016/j.jbtep.2015.10.007] [PMID]

6. Mathes BM, Morabito DM, Schmidt NB. Epidemiological and clinical gender differences in OCD. Current psychiatry reports. 2019;21(5):36. [DOI:10.1007/s11920-019-1015-2] [PMID]

7. Berman NC, Jacoby RJ, Sullivan AD, Hoeppner S, Micco JA, Wilhelm S. Parent-level risk factors for children's obsessive beliefs, interpretation biases,

$$
\begin{aligned}
& \text { بيشترى در مقابل تغيير ناشى از طرحواره درمانى و طرحواره } \\
& \text { درمانىهيجانى در آنها همراه مىباشد. مطالعه اى كه با نتايج } \\
& \text { مطالعه حاضر همسو نباشد، ييدا نشد. }
\end{aligned}
$$

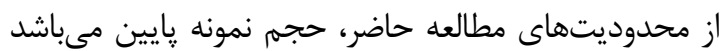

$$
\begin{aligned}
& \text { كه به دليل اجراى جلسات فردى و محدوديت زمانى امكان افزايش } \\
& \text { حجم نمونه نبود. لذا، يِشنهاد مىشود اين مطالعه با حجم نمونه } \\
& \text { بالاتر و به صورت زروهى در مطالعات آينده تكرار گردد. } \\
& \text { سياسگزןارى } \\
& \text { اين مقاله برگرفته از رساله دكترى مشاوره دانشعاه آزاد }
\end{aligned}
$$

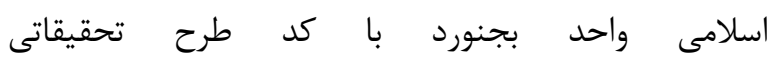

and obsessive-compulsive symptoms: A crosssectional examination. Journal of obsessivecompulsive and related disorders. 2018;18(1):8-17. [DOI:10.1016/i.jocrd.2018.04.002]

8. Fradkin I, Ludwig C, Eldar E, Huppert JD. Doubting what you already know: Uncertainty regarding state transitions is associated with obsessive compulsive symptoms. PLoS computational biology. 2020;16(2):e1007634.

[DOI:10.1371/journal.pcbi.1007634]

[PMID] [PMCID]

9. Dell'Osso B, Camuri G, Benatti B, Buoli M, Altamura AC. Differences in latency to first pharmacological treatment (duration of untreated illness) in anxiety disorders: a study on patients with panic disorder, generalized anxiety disorder and obsessive-compulsive disorder. Early intervention in psychiatry. 2013;7(4):374-80 [DOI:10.1111/eip.12016] [PMID]

10. Abramowitz JS, Arch JJ. Strategies for improving long-term outcomes in cognitive behavioral therapy for obsessive-compulsive disorder: Insights from learning theory. Cognitive and Behavioral Practice. 2014;21(1):20-31.

[DOI:10.1016/j.cbpra.2013.06.004]

11. Thiel N, Jacob GA, Tuschen-Caffier B, Herbst N, Kuelz AK, Hertenstein E, et al. Schema therapy augmented exposure and response prevention in patients with obsessive-compulsive disorder: Feasibility and efficacy of a pilot study. Journal of behavior therapy and experimental psychiatry. 2016;52:59-67. [DOI:10.1016/j.jbtep.2016.03.006] [PMID]

12. Olatunji BO, Davis ML, Powers MB, Smits JA. Cognitive-behavioral therapy for obsessivecompulsive disorder: A meta-analysis of treatment outcome and moderators. Journal of psychiatric 
research.

[DOI:10.1016/j.jpsychires.2012.08.020] [PMID]

13. Sunde T, Hummelen B, Himle JA, Walseth LT, Vogel PA, Launes G, et al. Early maladaptive schemas impact on long-term outcome in patients treated with group behavioral therapy for obsessivecompulsive disorder. BMC psychiatry. 2019;19(1):318. [DOI:10.1186/s12888-019-2285-2] [PMID] [PMCID]

14. Thiel N, Tuschen-Caffier B, Herbst N, Külz AK, Nissen C, Hertenstein E, et al. The prediction of treatment outcomes by early maladaptive schemas and schema modes in obsessive-compulsive disorder. BMC psychiatry. 2014;14(1):362. [DOI:10.1186/s12888-014-0362-0] [PMID] [PMCID]

15. Atalay H, Atalay F, Karahan D, Çaliskan M. Early maladaptive schemas activated in patients with obsessive compulsive disorder: A cross-sectional study. International journal of psychiatry in clinical practice. 2008;12(4):268-79. [DOI:10.1080/13651500802095004] [PMID]

16. Yoosefi A, RajeziEsfahani S, Pourshahbaz A, Dolatshahee B, Assadi A, Maleki F, et al. Early maladaptive schemas in obsessive-compulsive disorder and anxiety disorders. Global journal of health science. 2016;8(10):167. [DOI:10.5539/gjhs.v8n10p167] [PMID]

17. Kim JE, Lee SW, Lee SJ. Relationship between early maladaptive schemas and symptom dimensions in patients with obsessive-compulsive disorder. Psychiatry research. 2014;215(1):134-40. [DOI:10.1016/j.psychres.2013.07.036] [PMID]

18. Basile B, Tenore K, Luppino OI, Mancini F. Schema therapy mode model applied to OCD. Clinical Neuropsychiatry. 2017(6).

19. Young JE, Klosko JS, Weishaar ME. Schema therapy. New York: Guilford. 2003;254.

20. Taylor CD, Bee P, Haddock G. Does schema therapy change schemas and symptoms? A systematic review across mental health disorders. Psychology and Psychotherapy: Theory, Research and Practice. 2017;90(3):456-79. [DOI:10.1111/papt.12112] [PMID] [PMCID]

21. Sij ZD, Manshaee G, Hasanabadi H, Nadi MA. The Effects of Schema Therapy on Emotional SelfAwareness, Vulnerability, and Obsessive Symptoms Among Patients with Obsessive-Compulsive Disorder. Modern Care Journal. 2018;15(2). [DOI:10.5812/modernc.69656]

22. Douw L, Quaak M, Fitzsimmons SM, de Wit SJ, van der Werf YD, van den Heuvel OA, et al. Static and dynamic network properties of the repetitive transcranial magnetic stimulation target predict changes in emotion regulation in obsessivecompulsive disorder. Brain stimulation. 2020;13(2):318-26.

[DOI:10.1016/j.brs.2019.10.017] [PMID]
23. Naderi Rajeh Y, Zarghami M. The Efficiency of Emotional Schema Therapy on level of anxiety and depression, symptom and signs of patients suffering from Post-Traumatic Stress Disorder (PTSD). International Journal of Behavioral Sciences. 2017;11(3):114-20

24. Khosravani V, Ardestani SMS, Mohammadzadeh A, Bastan FS, Amirinezhad A. The Emotional Schemas and Obsessive-Compulsive Symptom Dimensions in People with Obsessive-Compulsive Disorder. INTERNATIONAL JOURNAL OF COGNITIVE THERAPY. 2020. [DOI:10.1007/s41811-02000075-6]

25. Leahy RL. Emotional schema therapy: A metaexperiential model. Australian Psychologist. 2016;51(2):82-8. [DOI:10.1111/ap.12142]

26. Morvaridi M, Mashhadi A, Shamloo ZS, Leahy RL. The effectiveness of group emotional schema therapy on emotional regulation and social anxiety symptoms. International Journal of Cognitive Therapy. 2019;12(1):16-24. [DOI:10.1007/s41811018-0037-6]

27. Abedi -Shargh N, Ahovan M, Doostian Y, Aazami $\mathrm{Y}$, Hosseini $\mathrm{S}$. The effectiveness of emotional schema therapy on clinical symptom and emotional schemas in patients with obsessive-compulsive disorder. Clinical psychology studies. 2017;7(26 ):149-63.

28. Hodgson RJ, Rachman S. Obsessional-compulsive complaints. Behaviour research and therapy. 1977;15(5):389-95. 7967(77)90042-0]

[DOI:10.1016/0005-

29. Sánchez-Meca J, López-Pina JA, López-López JA, Marín-Martínez F, Rosa-Alcázar AI, Gómez-Conesa A. The Maudsley obsessive-compulsive inventory: a reliability generalization meta-analysis. International Journal of Psychology and Psychological Therapy. 2011;11(3):473-93.

30. Ghassemzadeh H, Mojtabai R, Khamseh A, Ebrahimkhani N, Issazadegan A-A, Saif-Nobakht Z. Symptoms of obsessive-compulsive disorder in a sample of Iranian patients. International Journal of Social Psychiatry. 2002;48(1):20-8. [DOI:10.1177/002076402128783055] [PMID]

31. Young J, Klosko J, Weishaar M. Schema therapy: A practitioner's guide [H. Hamidpour, Z. Andooz Persian trans]. Tehran: Arjmand. 1998.

32. Moradi M, Akbari T, Dausti M. Relation between early maladaptive schemas and self differentiation in referrals to welfare centers. Procedia-Social and Behavioral Sciences. 2015;185:294-300 [DOI:10.1016/j.sbspro.2015.03.432]

33. Leahy RL. A model of emotional schemas. Cognitive and behavioral practice. 2002;9(3):17790. [DOI:10.1016/S1077-7229(02)80048-7]

34. Khanzadeh M, Edrisi F, Muhammadkhani S, Saidian M. Factor structure and psychometric properties of Emotional Schema Scale. J Clin Psychol. 2013;3(11):91-119. 
35. Young JE, Klosko JS, Weishaar ME. Schema therapy: A practitioner's guide. 3rd ed. New York: guilford press; 2006.

36. Leahy RL, Tirch D, Napolitano LA. Emotion regulation in psychotherapy: A practitioner's guide. Tehran: Arjmand; 2011.

37. Tenore K, Mancini F, Basile B. SCHEMAS, MODES AND COPING STRATEGIES IN OBSESSIVE-COMPULSIVE LIKE SYMPTOMS. Clinical Neuropsychiatry. 2018;15(6).

38. Khosravani V, Bastan FS, Ardestani MS, Ardakani RJ. Early maladaptive schemas and suicidal risk in an Iranian sample of patients with obsessivecompulsive disorder. Psychiatry research. 2017;255:441-8.

[DOI:10.1016/i.psychres.2017.06.080] [PMID]

39. Kwak K-H, Lee SJ. A comparative study of early maladaptive schemas in obsessive-compulsive disorder and panic disorder. Psychiatry research. 2015;230(3):757-62.

[DOI:10.1016/j.psychres.2015.11.015] [PMID]

40. Fergus TA, Bardeen JR. Emotion regulation and obsessive-compulsive symptoms: A further examination of associations. Journal of ObsessiveCompulsive and Related Disorders. 2014;3(3):2438. [DOI:10.1016/j.jocrd.2014.06.001]

41. Yap K, Mogan C, Moriarty A, Dowling N, BlairWest $\mathrm{S}$, Gelgec $\mathrm{C}$, et al. Emotion regulation difficulties in obsessive-compulsive disorder. Journal of Clinical Psychology. 2018;74(4):695709. [DOI:10.1002/jclp.22553] [PMID] 